\title{
Menores que migran solos y sistemas de protección a la infancia
}

\author{
Chabier Gimeno Monterde \\ Área de Trabajo Social y Servicios Sociales, \\ Facultad de Ciencias Sociales y del Trabajo, \\ Universidad de Zaragoza \\ <chabierg@unizar.es>
}

Los conocidos en España como 'menores extranjeros no acompañados' son los adolescentes que están migrando solos e irregularmente a Europa. Jóvenes que viven una doble condición de menores (a quienes hay que proteger) y extranjeros (a quienes hay que controlar y, en su condición de irregulares, expulsar). La legislación internacional de protección de la infancia dispone que todo menor solo sea tutelado por el Estado, al encontrarse en situación jurídica de desamparo. De ahí que la mayoría de estos adolescentes estén acogidos por las entidades públicas de protección de menores. Esta investigación sobre menores acogidos institucionalmente en Aragón ha incluido entrevistas, tratamiento estadístico de datos y la observación durante nuestra práctica profesional. Los resultados indican que las comunidades autónomas han recibido competencias explícitas e implícitas en la política migratoria española: explícitamente se les reclama que protejan a estos menores, mientras que implícitamente se les responsabiliza de evitar el 'efecto llamada' que dicha acogida supone.

\section{Palabras Clave:}

Menores, migración irregular, transnacionalismo, protección de la infancia, control migratorio. transnazionalismoa, haurtzaroaren babesa, migrazioen kontrola. 
En la adolescencia siempre pensamos en

tener un futuro, tenemos fuerza, pero no tenemos dinero... Nos gusta imitar a la gente mayor. [...] Allí empiezan. Luego llegan aquí... y encuentran totalmente lo contrario. [...]

Aquí es diez veces más difícil que ahí para ganarse la vida... Cuando no tienes ni papeles, ni nada..., no tienes nada que hacer, todas las ideas malas te vienen, cuando no tienes nada en los bolsillos (menor magrebî).

\section{Menores que migran solos}

Los denominados administrativamente 'menores extranjeros no acompañados' son aquellos jóvenes menores de edad que migran solos e irregularmente entre las regiones de la periferia económica y los países ‘desarrollados' (Quiroga, 2010: 22). La legislación internacional, al igual que la española, ampara su acogida en los sistemas de protección de menores hasta que alcanzan la edad adulta (López Azcona, 2008: 105).

En el curso de nuestra investigación sobre la migración de menores solos a Aragón, desarrollada entre 2007 y 2012, hemos concluido que las comunidades autónomas han recibido competencias explícitas e implícitas en la política migratoria española, como respuesta a la llegada de estos jóvenes y niños: explícitamente se les reclama que los protejan, mientras que implícitamente se les responsabiliza de evitar el 'efecto llamada' que dicha acogida supone. En este artículo sintetizamos las claves que nos llevan a esta conclusión.

Tanto nuestra experiencia profesional como las entrevistas con una amplia muestra de técnicos y adolescentes migrantes ponen de manifiesto una complejidad mucho mayor que la revelada inicialmente por los datos de los expedientes de protección, facilitados por la administración autonómica. Los discursos institucionales se refieren a menudo a un grupo homogéneo de menores que, conscientes de su estatus legal de desamparo, han migrado para ser atendidos por las autoridades locales. Sin embargo, nuestra investigación ha observado un grupo más heterogéneo. Las organizaciones humanitarias y los propios menores son conscientes de que, más allá de los adolescentes acogidos por las instituciones, hay otras vías de migración que permanecen ocultas, por voluntad de sus actores o por negligencia del Estado. El itinerario estandarizado por el trabajo social para la protección de los menores no acompañados es sólo uno de los que recorren. Hemos constatado la existencia de otros itinerarios paralelos, que en ocasiones se cruzan con el institucional.

Sobre los conflictos técnicos y éticos que esta heterogeneidad provoca en el trabajo social trata este artículo.

\section{Metodología}

En torno a 2006, hubo un incremento notable de menores no acompañados que migraban ilegalmente a España, lo que obligó a abrir nuevos centros de acogida en numerosas comunidades autónomas (Quiroga, 2010: 37). Partiendo del análisis cualitativo de nuestra praxis profesional con menores solos, iniciada en aquel periodo y centrada en la observación, posteriormente iniciamos un estudio desde la Universidad de Zaragoza que ha incluido entrevistas a técnicos de la administración pública local, responsables de las entidades privadas, trabajadores contratados por éstas, actores secundarios -como forenses o policías estatales-, así como a los propios menores. Accediendo a la base de datos del Sistema de Información de Menores de Aragón (SIMA), creada por el Gobierno autónomo, hemos obtenido información demográfica y administrativa, que se ha tratado estadísticamente. La observación en los centros de acogida o de formación y en los espacios urbanos adonde acuden o donde concurren estos menores ha completado el trabajo de campo.

\section{Menores y migración: dos enfoques}

A la hora de abordar una modalidad migratoria tan compleja, hemos recorrido dos caminos en paralelo: uno desde lo uniforme y otro intentando ver más allá. Nuestra primera aproximación se guió por los saberes clásicos de las ciencias sociales, intentando definir o delimitar de qué hablábamos, qué estaba sucediendo con los jóvenes a los que estábamos conociendo. Desde esa posición, concluimos que los aquí definidos como menores solos son los jóvenes y niños que migran de forma autónoma o semiautónoma a través de las fronteras entre las regiones más pobres y las más ricas del planeta (Suárez Navaz y Jiménez Álvarez, 2011: 16). Y que su denominación jurídica como 'menores extranjeros no acompañados'1 no muestra la heterogeneidad de orígenes y estrategias migratorias que esta investigación observaba. Para nosotros, estos jóvenes forman parte de una migración transnacional, entendiendo ésta como una estrecha relación entre su origen y su destino (Suárez Navaz, 2008: 6), pero también como la necesidad de investigar el anudamiento entre el control migratorio y la resistencia de los jóvenes migrantes a éste (ídem, 2008: 5).

En los estudios publicados en España sobre esta migración, abundan las aproximaciones cuantitativas, aunque las diferentes administraciones no han ofrecido hasta hoy datos con criterios uniformes ${ }^{2}$. En

\footnotetext{
${ }^{1}$ Para acercarse a las categorizaciones jurídicas de esta migración, puede recurrirse a las Observaciones Generales del Comité sobre los Derechos del Niño de Naciones Unidas, aprobadas en 2005, y en concreto, a la $n \div 0$, relativa al trato de los menores no acompañados y separados de su familia fuera de su país de origen.

2 En torno al equipo liderado por Violeta Quiroga, hay abundantes estudios: sobre el contexto español (Quiroga, 2010) y sobre comunidades autónomas, como Cataluña, País Vasco, Valencia o Madrid. Otros estudios se han realizado a través de las defensorías del pueblo: en Navarra, Asturias o Andalucía, por ejemplo.
} 
estos acercamientos apenas se refleja que los contextos de origen de los menores solos participan de un malestar un juvenil global, de una pobreza que no se asocia al hambre, sino a una falta de esperanzas de mejorar (Jiménez Álvarez y Vacchiano, 2011: 11). De ahí es de donde nace su voluntad de aceptar los ofrecimientos globalizados de la vida.

A menudo, esta migración se describe también como autónoma, aunque los menores no migran casi nunca solos, sino apoyándose en familias y redes de iguales asentadas a ambos lados de las fronteras (Suárez Navaz, 2008: 7). 0, en el peor de los casos, lo hacen 'mal acompañados' por adultos que no los asisten o los explotan (Quiroga y Soria, 2010: 26). Revisando lo escrito hasta hoy, también observamos que son frecuentes los discursos basados en los derechos de la infancia que recurren a su victimización. Estas posiciones también pueden contribuir a ocultar la capacidad de agencia de los menores solos, como actores migratorios con voz y voluntad propia (O’Higgins, 2012: 80 y 82).

En la base de esta victimización, las legislaciones europea y española se han movido de forma pendular, una vez aprobada la Convención de Derechos del Niño, en 1989. Primero, desplegando derechos para estos jóvenes que se categorizan como 'desamparados' y a los que se reconoce la posibilidad de ser acogidos institucionalmente por los Estados de destino (López Azcona, 2008: 105). Pero después iniciando una involución en la universalidad de estos derechos, a través de una regulación estatal de dichas acogidas cada vez más restrictiva, con lo que se acompaña el cierre progresivo de las fronteras de Europa frente a su periferia (Jiménez Álvarez, 2011: 102).
Con todo, este primer acercamiento a través de las ciencias sociales, los derechos humanos o las perspectivas jurídicas no ha podido explicar toda la diversidad que habíamos percibido en la práctica profesional. Esto se debe a la posición como ‘externos' que adoptan estos y otros saberes clásicos (Bergua, 2007: 50), a menudo 'ciegos' ante estrategias y trayectorias migratorias nacidas en la irregularidad administrativa. Algo que no ocurre en otras investigaciones surgidas en los últimos años desde la intervención social con menores solos ${ }^{3}$, y que nos han señalado la necesidad de buscar otras formas de saber.

En esta segunda aproximación, nuestra experiencia como profesionales del trabajo social concluye que esta disciplina busca una homogeneidad de resultados al final de la acogida institucional de los menores 'desamparados': esto es, un joven académicamente formado, insertado laboralmente, regularizado administrativamente y con una conducta social adaptada a su perfil de 'rescatado' de la exclusión social ${ }^{4}$. Al mismo tiempo, por debajo de esta uniformidad, coexiste una heterogeneidad de procedimientos que se resisten a esa simplificación de la migración: la ocultación de identidades, la falsificación de edades y otras estrategias para acceder a la acogida. Pero también el consumismo, el hedonismo y la rebeldía propias de su condición de jóvenes globales, alejados del estigma de 'víctimas' que el Estado les atribuye.

Siguiendo, entre otros, al sociólogo aragonés José Ángel Bergua, nos planteamos que las políticas migratorias dirigidas a los menores solos son percibidas por éstos como un ejercicio de poder u orden, entendido éste como la búsqueda de una

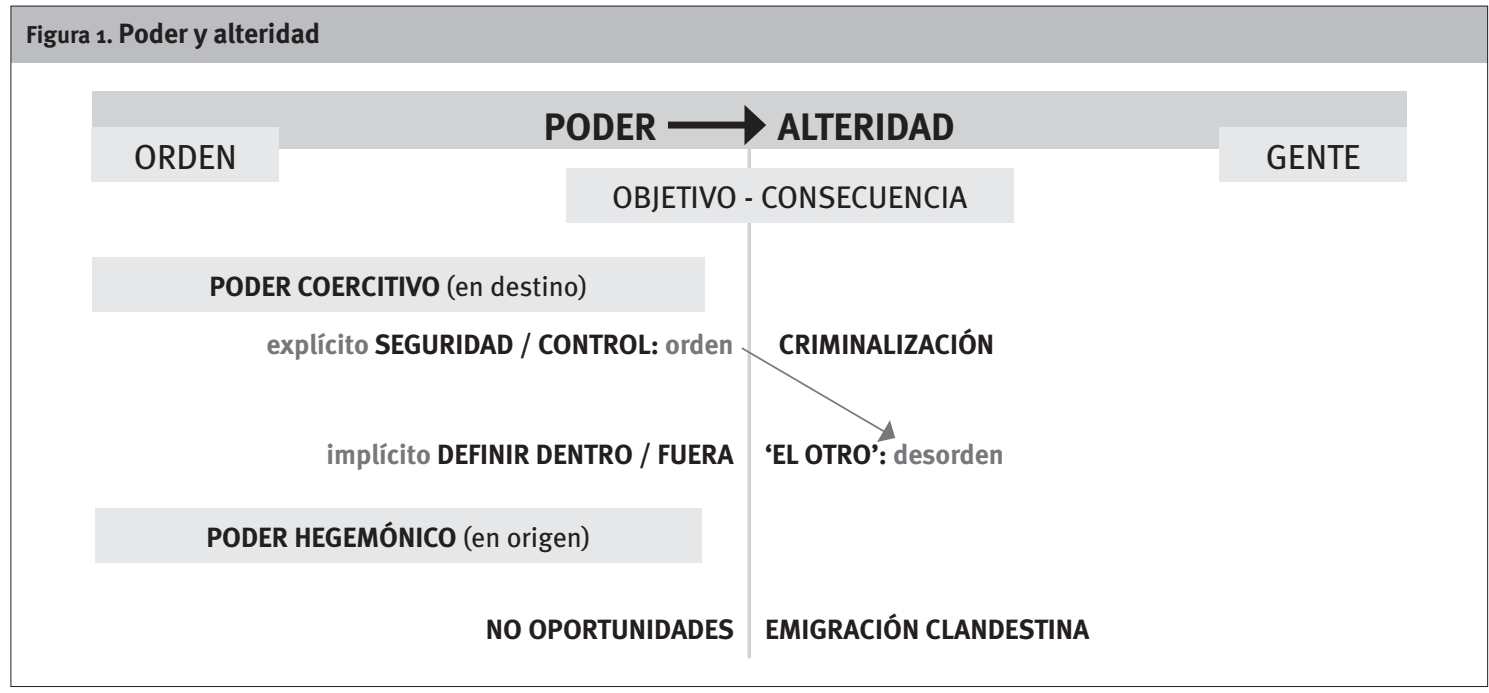

Fuente: Gimeno Monterde (2011, 851).

${ }^{3}$ De entre ellas, son referencia para nuestra investigación los trabajos de Empez (2007, 2009), Rodríguez García de Cortázar (2008), y Rodríguez García de Cortázar y González Santamaría (2011).

${ }_{4}$ Coincidimos así con el análisis de López Riopedre (2011) sobre la denominada 'industria del rescate'. 
uniformidad, una estabilidad 5 , mientras que los menores que migran solos suponen para el Estado un desorden, al haber accedido a su territorio por una 'grieta' en la legislación, que obliga a su protección (Empez, 2007: 12). El Estado pretende disciplinar jurídicamente esta migración mediante las leyes y uniformar a los menores mediante el trabajo social, anulando progresivamente su capacidad de subvertir el orden al burlar las fronteras. Y la resistencia anudada de los menores es buscar nuevas maneras de eludir ese control, bien migratorio, bien del trabajo social. Se configuran así como 'gente': algo impredecible y que se aleja constantemente del equilibrio (Maffesoli, 2004: 109; Bergua, 2007: 40).

Al asumir esta relación entre el Estado y los menores solos, nos hemos implicado también en debates académicos y técnicos sobre la ética de estas investigaciones que parten de una relación profesional con los jóvenes ${ }^{6}$. Hemos sido conscientes de que la información que, como científicos, recabamos puede ser utilizada por políticos y técnicos para estabilizar el desorden que los menores solos introducen en el control de flujos migratorios7. Pero también hemos concluido que es necesario investigar de esta manera para mostrar que las fronteras y el trabajo social construidos por el orden son 'burlables', al mismo tiempo que saciamos nuestro impulso por conocer aquello con lo que convivimos como trabajadores de lo social (Bergua, 2005: 50).

\section{Menores solos acogidos en Aragón}

Con esta combinación de saberes clásicos y no clásicos, hemos accedido a datos y discursos que hemos ordenado en dos grandes apartados para su análisis y posterior difusión: uno dedicado a la acogida institucional; $y$ otro, a aquello que se sustrae a la acogida, como los otros actores y escenarios de esta migración, o el imaginario de los jóvenes.

Para el análisis de la acogida institucional, ha resultado fundamental la colaboración del Instituto Aragonés de Servicios Sociales (IASS, Gobierno de Aragón), que ha autorizado el acceso a los expedientes de protección de los menores solos ${ }^{8}$, y facilitado el contacto con técnicos de entidades públicas y privadas.

${ }^{5}$ Sobre nuestro análisis de las políticas sociales en términos de estabilidad e inestabilidad, orden y desorden, véase lo expuesto en Gimeno Monterde (2011), donde analizamos la alterización de los menores solos (Figura 1).

${ }^{6}$ En esta reflexión, nos hemos guiado por los debates con otras educadoras-investigadoras, como Empez (2009), así como por la aportación de Bergua (2007: 74) sobre aquellos científicos que compatibilizamos lo vivido con lo estudiado, como actores en uno de los frentes.

7 Véanse al respecto los trabajos de Cabrera (2005) sobre los menores solos marroquíes.

${ }^{8}$ Esta investigación es la primera en el Estado español que ha accedido a todos los expedientes de menores solos desde el inicio del flujo migratorio, además de al mayor número de variables administrativas estudiado hasta hoy. Ello ha marcado una nueva senda en la colaboración de los Gobiernos autonómicos con quienes investigamos esta migración. El análisis con el paquete estadístico SPSS está disponible para todos los equipos de investigación interesados, y próximamente, se podrá consultar en la web del Instituto Aragonés de Servicios Sociales.
El análisis de los datos estadísticos sobre los menores solos acogidos institucionalmente en Aragón entre 2000 y 2010 muestra un colectivo similar al que recogen otros estudios publicados en España: adolescentes mayoritariamente de entre 15 y 17 años, procedentes casi siempre del Magreb (tres cuartas partes) 0 del África subsahariana (una quinta parte), de los que menos de un $5 \%$ son niñas (cfr. Gráficos 1 y 2).

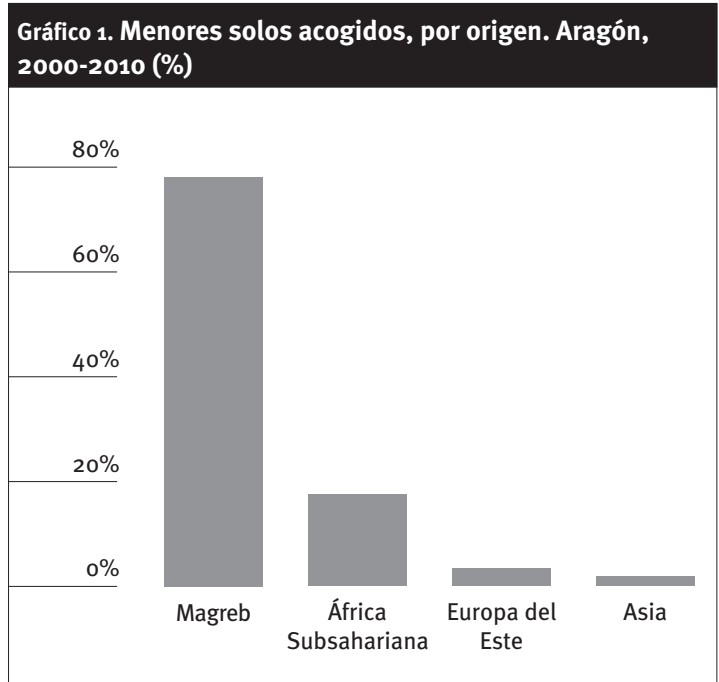

Fuente: Elaboración propia a partir de datos del Sistema de Información de Menores de Aragón.

Gráfico 2. Menores solos acogidos, por edad a la apertura del expediente. Aragón, 2000-2010 (\%)

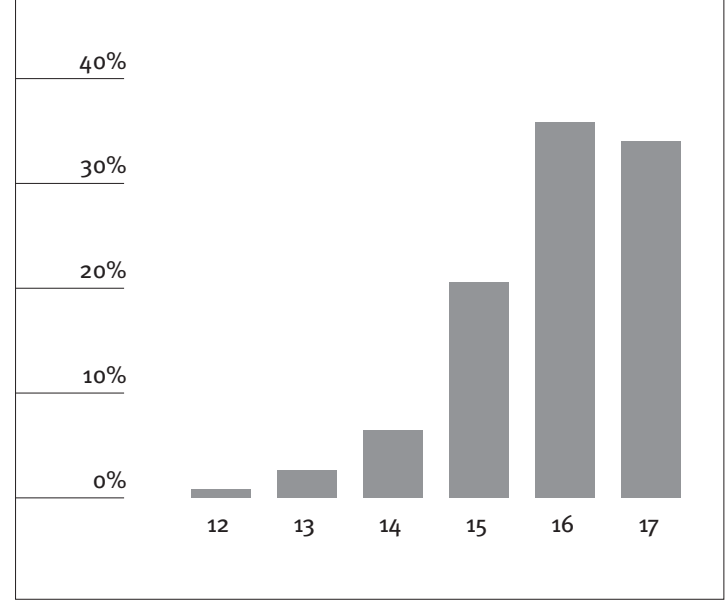

Fuente: Elaboración propia a partir de datos del Sistema de Información de Menores de Aragón.

Nuestro análisis estadístico concluye también que la llegada de menores a la acogida en Aragón ha pasado por varias etapas, que después describiremos, así como que al contrastar los datos con las entrevistas y otras fuentes documentales, se 
evidencia que no aparecen otros menores solos que también llegaron a Aragón y cuyo volumen podría ser significativo: por un lado, los que en los primeros años del siglo llegaban a los centros de acogida y se fugaban de ellos a los pocos días; y, por otro, los menores que no fueron detectados por el Estado y permanecían 'invisibles', en ocasiones 'mal acompañados' por redes de explotación.

También en otros ámbitos estudiados, como ocurre con los orígenes y viajes de los jóvenes, el trabajo social puede haber tenido una visión uniforme, mientras que esta investigación ha percibido una mayor pluralidad. Entre los menores solos observados, no se dan únicamente los orígenes delimitados por el trabajo social en los perfiles 'magrebí' y 'subsahariano’, sino que es preciso hablar más apropiadamente de jóvenes de origen urbano y rural, magrebíes de etnia árabe y de etnia bereber, subsaharianos occidentales y del África central.

Esta misma estandarización se da en la percepción del trabajo social sobre las situaciones de origen (ADCARA, 2008: 53), frecuentemente precarizadas por la globalización económica, pero entre las que también se encuentran otras de jóvenes provenientes de entornos con menor riesgo social, que chocan con los parámetros de victimización establecidos por el trabajo social. El trabajo social extiende estas categorizaciones a la aparente universalidad de la participación de las familias en la decisión migratoria y en el diseño del viaje, que responde igualmente a estereotipos (ídem: 52). La investigación muestra, al contrario, una pluralidad de situaciones, en las que las familias conocen o no el viaje antes de su inicio, y comparten o rechazan la decisión de migrar de los menores.

Mi madre no sabía nada que yo venía... Algún día le dije: "Mamá, me voy a España”. Y me dijo: “¡Ni hablar, ni lo sueñes!”. Pero he venido hasta aquí y luego le llamé y no ha dicho nada (menor subsahariano).

En definitiva, el punto ciego en el que la posición de externos sitúa al trabajo social afecta a su conocimiento de los orígenes y viajes de los menores, hasta el punto de no comprender la existencia de múltiples rutas que pasan o llegan a Aragón, al amparo de las familias y redes de iguales, y que incluyen no sólo otras comunidades autónomas, sino también complejas etapas en otros Estados europeos?.

\footnotetext{
9 "Mi hermano estaba aquí [España] y un día llamó a mi tío [Francia] y le contó eso..., que un chico vino y lo tutelaron en un piso, le dieron los papeles y estudió... Me pasaron [el teléfono] a mí: ‘¿Si vienes, vas a estudiar...?’. Yo dije: “Sí” [...]. Me llevaron a un autobús, que cogía pasajeros de Francia a Marruecos [...], con un hermano de [un] amigo de mi hermano [...]. Llegamos por la noche aquí [Zaragoza] [...]. Al día siguiente, me acompañó un amigo de [...] estuvo en Francia también... Él me llevó a la comisaría, a la central... Yo tenía miedo... Entendí que le dijo que vino debajo de un autobús... 'Si te pregunta cualquier cosa, tú dile que sí’ [...]. Cuántos años [...]. Luego llegamos al COA [Centro de Observación y Acogida, Zaragoza]" (menor
} magrebí).

\section{Menores solos: análisis institucional}

Esta complejidad, recurrente en toda la investigación, está presente también en el cuerpo central de ésta, el análisis institucional, que aborda la incidencia y la adaptación mutuas entre los jóvenes que migran solos y el sistema de protección de la infancia en Aragón. Así, como intuíamos, se ha puesto de manifiesto la existencia de un modelo aragonés de gestión de la protección de menores solos.

En el plano legislativo, la adaptación a esta migración se plasmó, una vez asentado el flujo migratorio, en la elaboración del Reglamento 190/2008 y de diversos documentos técnicos, como guías y protocolos ${ }^{10}$, que regulan su acceso a los recursos de acogida institucional, siguiendo criterios garantistas. En cuanto al desarrollo de lo legislado, la base común de este modelo con el de otras comunidades autónomas está en la externalización de sus servicios a las denominadas 'entidades sociales' (Monteros, 2007: 174). Aunque el modelo aragonés se ha diferenciado también por su estabilidad, por la preponderancia de los recursos situados en la ciudad de Zaragoza y por la adopción burocrática de los protocolos estatales de acogida de menores solos desde el momento en que éstos se ponen en marcha (Observatorio de la Infancia, 2005).

Esta respuesta burocrática ante la aparición de una nueva figura de jóvenes desamparados se refleja en la información administrativa sobre las vías de llegada a la acogida institucional en Aragón (Gráfico 3), una información que, con todo, no siempre concuerda con lo observado durante el trabajo de campo. Mientras que los expedientes señalan como causa de su inicio que la mayoría de los menores son detectados por la Administración, las entrevistas indican que muchas de esas acogidas responden al conocimiento de las vías de acceso al sistema de protección por el propio menor. Los actores externos al sistema de protección, como otros menores compatriotas y las familias en Europa, han guiado a muchos menores solos en su 'autocandidatura' en Aragón ${ }^{11}$.

Algo similar ocurre al contrastar otras variables de los expedientes con la información ofrecida por técnicos y menores. Si observamos los motivos de archivo (Tabla 1), la mayoría de los expedientes de acogida de los menores solos se cierran cuando éstos alcanzan la mayoría de edad, cumpliendo así los objetivos de la acogida.
10 Pueden consultarse en la web del Instituto Aragonés de Servicios Sociales: 〈http://iass.aragon.es/menores/menores_apoyo.htm〉.

11 "Porque entre ellos se mandan la información con los móviles: [...] “En Zaragoza hay plazas”” (profesional de entidad pública). 


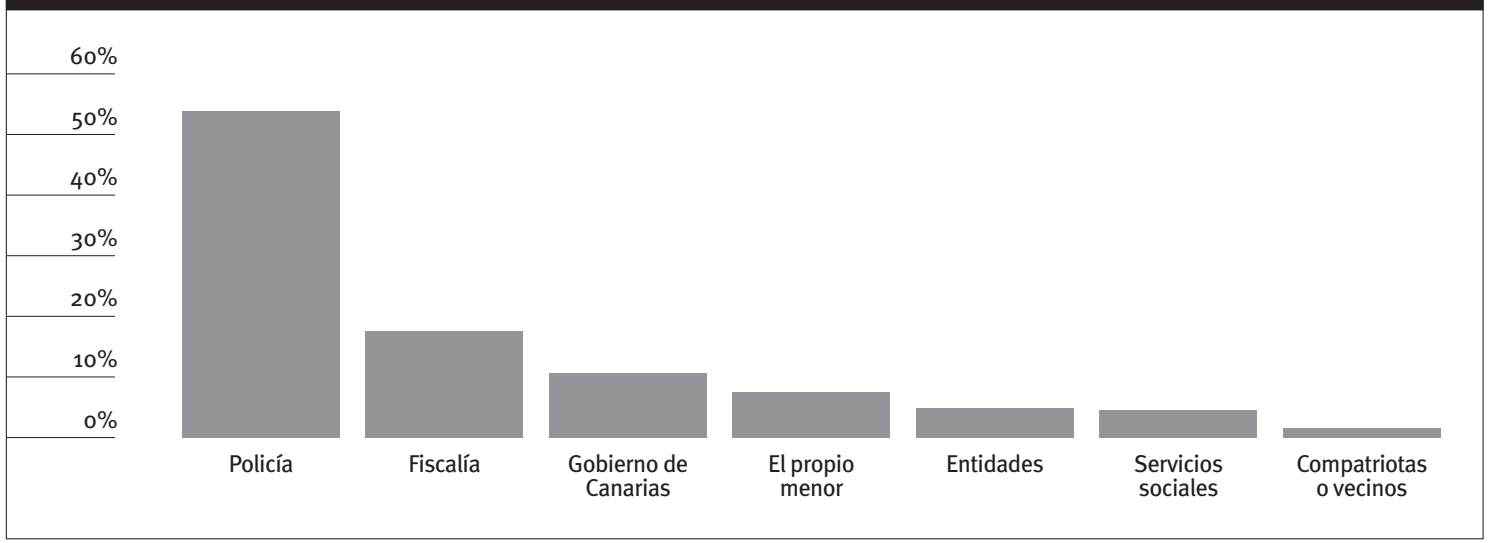

Fuente: Elaboración propia a partir de datos del Sistema de Información de Menores de Aragón.

Tabla 1. Motivos aludidos para cerrar expedientes de menores solos, por origen de los menores. Aragón, 2000-2010 (\%)

\begin{tabular}{l|c|c|c|c|c}
\cline { 2 - 5 } & Localización & No archivado & $\begin{array}{c}\text { Cumplimiento } \\
\text { de objetivos o mayoría } \\
\text { de edad }\end{array}$ & Traslado & Total \\
\hline Magreb & 17,1 & 16,2 & 61,1 & 5,6 & 100,0 \\
\hline África subsahariana & 3,8 & 28,8 & 65,4 & 1,9 & 100,0 \\
\hline
\end{tabular}

Fuente: Elaboración propia a partir de datos del Sistema de Información de Menores de Aragón.

Pero para ver más allá de esta aparente estabilidad, es preciso detenerse en los expedientes archivados por la fuga o ilocalización del menor, que representan una quinta parte de los expedientes cerrados. Mayoritariamente, se trata de varones magrebíes o de Europa del Este, mayores de 15 años y que desaparecen en el primer año de la acogida. Estos datos estadísticos reflejan a su vez un 'saber común', muy presente en los discursos de los técnicos, y que relaciona las diferencias en la duración de los expedientes con las diferencias en la adaptación a la acogida según el origen de cada menor solo. Datos y técnicos coinciden así en que los jóvenes subsaharianos se han 'adaptado' mejor a los itinerarios de protección, pues no se fugan (sólo lo hizo un 3’8\%), llegan a Aragón en edades muy próximas a la edad laboral y acceden en mayor porcentaje a las medidas de apoyo para jóvenes que salen de la acogida por mayoría de edad.

Además de servir para resituar los datos estadísticos ofrecidos por los expedientes de acogida, la observación y las entrevistas también nos permiten analizar la asignación de los menores solos a los recursos residenciales. Estas derivaciones se han basado en del trabajo social en los centros de primera acogida. Los menores categorizados como más adaptados a la estandarización del trabajo social han sido derivados a pisos, donde se han dado itinerarios con mayor éxito. Al contrario, los categorizados como menos adaptados han sido derivados a residencias colectivas, donde han convivido con conflictos más frecuentes y más casos de fugas, motivos por los que a menudo son estigmatizados (Gimeno Monterde, 2012a: 273).

La experiencia más reseñada en las entrevistas ha sido la residencia 'Casa de San José', único recurso específico implementado para menores solos, donde la combinación de su situación geográfica, la concentración de menores solos en los que se habían observado conductas menos adaptadas al trabajo social y la inexperiencia de la entidad gestora la conformaron como un gueto (Gimeno Monterde, 2012a: 274). La posterior evolución negativa de muchos de los menores solos allí acogidos evidencia el fracaso de este modelo residencial en Aragón.

\section{Ciclo del flujo migratorio}

Dentro de este mismo análisis institucional, el análisis cuantitativo de los expedientes de acogida también ha reforzado otra conclusión derivada de las entrevistas y las fuentes documentales: el flujo de la migración de menores solos a Aragón responde a las fases de un ciclo (Gráfico 4). Un ciclo marcado por el progresivo aumento inicial y el actual decaimiento en el volumen de las acogidas, y que tiene su origen en la adaptación mutua entre la Administración y los menores solos. 
Fuente: Elaboración propia a partir de datos del Sistema de Información de Menores de Aragón.

La fase inicial del ciclo, a partir de 2000 , se caracterizó por un goteo en la apertura de expedientes de tutela, que responde a la práctica institucional de una acogida precarizada. A los menores solos detectados y remitidos a los centros de primera acogida se les abrían expedientes denominados 'previas', que se dilataban en el tiempo y no generaban una 'tutela firme' de forma automática, por lo que los menores no veían en Aragón una vía efectiva para regularizarse 0 asentarse, y se fugaban a otras comunidades autónomas ${ }^{12}$. De esta manera, los centros de primera acogida actuaban como filtros para evitar la absorción por el sistema de protección de este flujo de menores, que pueden haberse percibido como “no-nuestros” (Suárez Navaz, 2004: 37).

Durante este primer periodo, los menores ocultaban su identidad o su documentación y protagonizaban otras estrategias de resistencia frente a los itinerarios estandarizados que se les planteaban desde el trabajo social de la acogida, itinerarios ajenos a sus proyectos migratorios, a menudo con base económica. Aunque esto derivase en conflictos de convivencia en los centros, y en ocasiones éstos se desbordaran, la situación no se subsanó, lo que contribuyó a disuadir a los menores sobre la viabilidad de su acceso a la regularización administrativa por medio del sistema de protección.

Entre 2006 y 2008, la Administración aragonesa se adaptó a los requerimientos del Estado central en

${ }^{12}$ En los informes sobre la Situación de los menores en Aragón emitidos por el defensor del pueblo autonómico (Justicia de Aragón) entre 2000 y 2003 , se consignan los siguientes datos sobre menores solos fugados respecto al total de las fugas en el centro de primera acogida de Zaragoza: 22 de 23, 30 de 39, 60 de 73 y “la mayoría” de 26 , respectivamente. Esta información es común en otros informes institucionales (IASS-ADCARA, 2005: 72). materia de protección de los menores solos (derivados del Protocolo emitido por el Observatorio de la Infancia en 2005) y simplificó su propio protocolo de acogida, asumiendo la tutela firme a los diez días de detectar al menor. Este cambio en la praxis administrativa coincide estadísticamente con el decaimiento de las fugas de menores solos y el aumento de la estancia media en su acogida ${ }^{13}$. Las entrevistas también señalan que, en este periodo, los menores que llegan a Aragón para asentarse ya conocen las dificultades para regularizarse en otras comunidades autónomas, que en ocasiones pueden derivarlos a Aragón (como ocurría con el País Vasco), y reciben también información de sus redes de iguales y familiares sobre las mejores perspectivas de regularización en Aragón.

\section{No me gustó [centro en el País Vasco] [...]. A lo mejor te quedas ahí y no consigues nada [...]. Ellos [los educadores] me compraron un billete a Zaragoza [...]. Había jóvenes ahí que me dijeron que Zaragoza, mejor (menor magrebî).}

En la última fase, que abarca desde 2009 hasta hoy, se ha producido una diversificación de los orígenes y un descenso en el volumen de menores solos acogidos en Aragón (Gráfico 5), al igual que en casi toda España. Los menores marroquíes han perdido peso relativo en el conjunto, y bien proceden de otras comunidades autónomas donde han protagonizado conflictos en el sistema de protección, o bien presentan conductas de 'hiperadaptación' a éste. Por el contrario, se ha incrementado el porcentaje de menores solos de origen subsahariano, con mayor

${ }^{13}$ De manera que, como refleja el Gráfico 4, el descenso en los expedientes nuevos convive con unas cifras mayores en el total de acogidos, a partir de 2006-2007. 


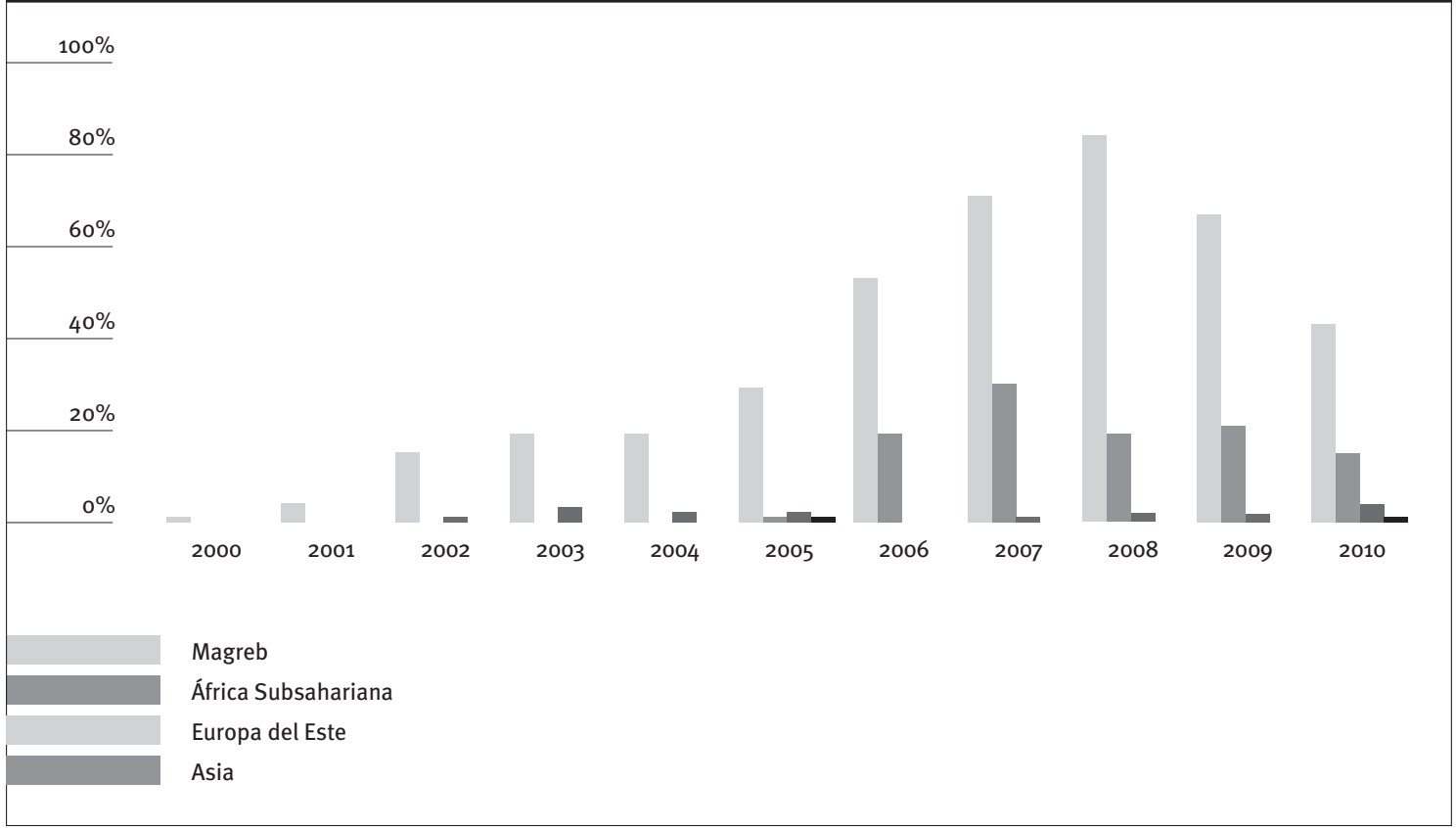

*Datos a 31 diciembre de cada año.

Fuente: Elaboración propia a partir de datos del Sistema de Información de Menores de Aragón.

diversidad de nacionalidades y frecuentes conflictos en torno a la veracidad de las edades consignadas en sus pasaportes.

El intercambio de saberes en los encuentros de profesionales e investigadores en los que hemos participado en España, Marruecos y Francia nos permite concluir que el descenso en el volumen de menores solos está ligado a la creación por la Administración central de un registro centralizado e informatizado donde se recogen datos biométricos de cada menor solo detectado (ADEXTRA), lo que dificulta su movilidad y cambio de identidad como estrategias de acceso al sistema de protección. Igualmente, también está ligado al papel de Marruecos como Estado de contención y regulación de estos flujos migratorios juveniles.

\section{Biopolítica y tensiones en el trabajo social}

Como conclusión de este análisis de la acogida institucional de los menores solos, desde esta investigación planteamos un doble enfoque: por una parte, vinculando la protección de menores al control migratorio; y por otra, desgranando las tensiones con las que convive tal vinculación.

De forma general, los sistemas de protección de menores europeos desarrollan dispositivos con el fin de corregir, encauzar y uniformar las conductas, estableciendo así una relación de poder "biopolítica" (Cayuela, 2008: 34), que va más allá de las accio- nes individuales de los técnicos. En el caso de los menores solos, esta biopolítica se ha desarrollado mediante la práctica institucional de lo que aquí hemos denominado “bioselección” (Gimeno Monterde, 2012a: 273 y 281).

La bioselección con los menores solos se habría iniciado a comienzos de este ciclo, al filtrar su acceso al sistema de protección mediante las dilaciones en los centros de primera acogida, configurando así Aragón como un territorio 'de paso', en el que era difícil asentarse y regularizarse. Continuaría posteriormente durante el crecimiento del flujo de menores solos acogidos, derivándolos a unos recursos residenciales o a otros en función de su conducta en el centro de primera acogida ${ }^{14}$. Y en el último periodo del ciclo estudiado, se produciría al alcanzar los menores solos tutelados la mayoría de edad, accediendo a los recursos de apoyo para extutelados (Programa de Emancipación Personal) sólo aquellos que han completado su itinerario de acogida con un resultado homogeneizado: esto es, joven que busca empleo y se mantiene en formación ${ }^{15}$.

${ }_{14}$ "Y me dijeron: 'Te vamos a mandar [a] un piso [al] que jamás [a] ninguno mandan ahí.. Porque todos [los] que vienen aquí [COA] fuman porros y eso, y no quieren mandarles porque en ese [piso] hay gente buena [...]. Al principio, cuando estuve en el COA, me dijeron: 'Si te portas bien, te mandan a un piso donde hay bien; si te portas normal, te mandan a uno normal; si te portas mal, te mandan con gente que [se] portan mal [...], roban, que hacen lo que sea; a ésos, a [residencia]"' (menor magrebí).

15 "Tenemos una seria dificultad: estos chavales son los últimos a la cola de tener ese tipo de recursos [de emancipación] [...] el número de plazas es limitado [...] si hay que elegir, la sociedad elige" (profesional de entidad pública). 
¿Qué consecuencias ha tenido este intento de encauzar la migración de menores solos? La más evidente han sido las tensiones en los procedimientos de acogida institucional, entre las que destacaremos brevemente cuatro:

- En primer lugar, la protección a los menores en situación de desamparo se realiza mediante la tutela administrativa. En el caso de los menores solos, la dilación en su aplicación en el primer periodo del ciclo estudiado atendía a criterios de política migratoria y pretendía evitar el 'efecto llamada' de una tutela aplicada de forma 'automática' y universal.

- En segundo lugar, la determinación de la edad de los menores solos detectados en Aragón se ha desarrollado como una práctica precarizada, aun cuando los técnicos competentes han diseñado protocolos que podrían garantizar una eficacia pionera en el Estado (Justicia de Aragón, 2010). Esta situación ha derivado de una decisión política y ha contribuido a generar una incertidumbre entre los menores solos ante este requisito de acceso al sistema de protección.

- En tercer lugar, y aunque en Aragón se ha asumido la edad que certifican los pasaportes que aportan los menores solos, las tensiones en la regularización documental de éstos se han plasmado, por un lado, en la dilación de las tramitaciones en los casos de menores con conductas inadaptadas al trabajo social (Gimeno Monterde, 2012a: 280); y por otro lado, en los problemas para documentar a los menores acogidos en fechas próximas a la mayoría de edad. Para esta investigación, ambas prácticas habrían implicado discrecionalidad, pues estaban sometidas al criterio de la Administración, y no a la normativa (Durán, 2007: 10).

- Y en cuarto y último lugar, la mayoría de los extutelados, independientemente de su nacionalidad, acceden a la edad adulta sin unos apoyos que desde la Administración, se consideran de elevado coste. En paralelo, la baja cualificación y escasa empleabilidad de los menores solos ha representado, y representa, una grave dificultad para continuar renovando su residencia legal, siempre vinculada a un contrato laboral.

A la vista de estas tensiones, es preciso matizar que nuestra observación inicial desde la práctica profesional analizaba la migración de estos jóvenes como el acceso a la fortaleza europea por una puerta exclusiva para menores de edad, que habíamos denominado "la puerta del Imaginarium" (Gimeno Monterde, 2010: 67). Pero nuestra investigación, sin embargo, concluye que este acceso se ha transformado hoy día en una puerta giratoria: cuando gran parte de los menores que migraron solos alcanzan la edad adulta y abandonan la acogida institucional, vuelven a su situación administrativa irregular de partida. Como consecuencia, constatamos el incremento de proyectos migratorios de extutelados que se dirigen ahora hacia otros Estados europeos.
Las prácticas de bioselección y las tensiones administrativas en torno a la acogida institucional de los menores solos indican, en definitiva, que los sistemas de protección de menores han recibido implícitamente competencias en el control de este flujo migratorio. Todo ello dentro de una lógica casi siempre ajena a los haceres y saberes de unos profesionales de la intervención social altamente vocacionados y claramente incómodos ante esta muda atribución (Gimeno Monterde, 2010: 68).

\section{Actores y escenarios fuera del sistema de protección}

Esto para ti, para que sabes lo que pasa en los centros de menores. Mucha gente no sabe, éstos vienen a robar, ¿por qué? (menor magrebî).

Llegamos así a la segunda parte de nuestro análisis, el que surge de la observación durante la práctica profesional, como curiosidad por todo lo que acompañaba al trabajo social con los menores que migran solos y, a la vez, se sustraía a éste, estando en la base de los conflictos y contradicciones de nuestras praxis como técnicos.

En primer lugar, quisimos contrastar una de nuestras hipótesis, la existencia de expectativas previas de acogida en el sistema de protección entre los menores y su entorno, algo que forma parte del discurso institucional observado en los técnicos de acogida. Nuestro análisis de las estrategias migratorias de los menores concluye que este discurso es una nueva uniformización de una migración heterogénea, pues los menores solos migran con o sin el conocimiento previo del sistema de protección, así como con un proyecto migratorio definido o sin él (Gimeno Montarde, 2012b). Este discurso institucional sobre las expectativas previas está vinculado, más bien, a la percepción de los menores solos como subversión del asistencialismo que empapa el trabajo social instituido ${ }^{16}$, ya que sus conductas dentro del sistema de protección, a menudo, los han identificado como 'consumidores' de éste, y no como 'usuarios' victimizados (Gimeno Monterde, 2010: 66).

En segundo lugar, entender lo que el trabajo social no podía, o no quería, saber de la migración de los menores solos nos ha llevado a buscar actores y escenarios ajenos al sistema de protección. De esta manera, la investigación ha distinguido entre un itinerario lineal y estandarizado con el que el trabajo social interviene sobre la migración de los menores

\footnotetext{
16 "Se está apreciando un cambio de perfil del usuario, apareciendo cada vez más menores inmigrantes marroquíes teóricamente no acompañados, pero de los que se sospecha que sí lo están, que si bien sus padres permanecen en Marruecos, aquí tienen familia (tíos, hermanos mayores...), y dada la imposibilidad de reagruparse, utilizan este recurso para la atención y cuidado de los menores y, a ser posible, su regularización, pervirtiendo así el sistema de protección, pues se parte de la base de que el menor estará mejor con su familia que en un centro" (Justicia de Aragón, 2007: 122).
} 
solos y en el que la protección es una etapa final; y una realidad observada que nos muestra múltiples itinerarios paralelos, entre los que la acogida institucional tan sólo es una etapa más, no el destino final (Gimeno Monterde, 2010: 63).

Esto se explica cuando los menores solos entran, salen o se mantienen al margen del itinerario estandarizado (Suárez Navaz, 2006: 13) para recorrer otros itinerarios junto a actores a los que el trabajo social no puede o no quiere acceder, pues no sabe o no puede encauzarlos (Bergua, 2011: 199). Entre estos actores, están las redes de iguales y las familias de los menores, que ponen en cuestión la homogeneización de categorizaciones jurídicas o científicas ${ }^{17}$, como ‘desamparados' o ‘no acompañados':

- Las redes de iguales están formadas por otros jóvenes compatriotas con presencia a ambos lados de la frontera, así como dentro y fuera de los centros de acogida, y conforman el principal referente de socialización de la mayoría de los menores solos.

- Por su parte, la familia nuclear y la extensa han situado el sistema de protección en un escenario transnacional donde los servicios sociales se han internacionalizado, permitiendo a las familias hacer un consumo estratégico de la acogida institucionalizada, difícil de eludir desde la lógica burocrática del 'desamparo'18.

El trabajo social, como agente externo a esta migración, ha percibido sus estrategias de resistencia como una perversión (Justicia de Aragón, 2007: 122). De ahí que se hayan desarrollado, entre otros, discursos institucionales sobre el 'desapego' de las familias de origen hacia los menores solos ${ }^{19}$. Estas simplificaciones, junto a la limitación territorial de sus intervenciones, han impedido a la Administración asumir la presencia de las redes familiares en otras comunidades autónomas, en Aragón o en otros Estados europeos.

${ }^{17}$ Las categorías no sólo simplifican la complejidad. Para Monteros (2007: 174), las categorías que se establecen son performativas: esto es, no sólo nombran, sino que también construyen. El Gobierno necesita conocer lo que tiene que ser gobernado. De ahí su insistencia en elaborar categorías de personas a partir de definiciones que intentan homogeneizar procesos bien diferentes. La construcción de estos saberes es indispensable para la gobernanza.

${ }_{18}$ Saskia Sassen (2003: 82) llega a afirmar que los derechos humanos internacionales, en tanto se encuentran enraizados en los documentos fundacionales de los Estado nacionales, son hoy día una fuerza que puede socavar la autoridad exclusiva del Estado sobre sus poblaciones y, por tanto, contribuir a la transformación del sistema interestatal y del orden legal internacional. La pertenencia a Estados nacionales meramente territoriales deja de ser la única base para el ejercicio de un derecho. Todos los residentes, sean o no ciudadanos, pueden reclamar este ejercicio de los derechos humanos.

19 "Los marroquíes ya no traen proyecto migratorio. Es una situación obligada, y te cuentan que si el padre es médico allí, por ejemplo. Y luego se ha comprobado que hay algunos de familias ricas marroquíes. De hecho, no es una situación distinta de la que se vive en Andalucía, donde se propuso denunciar a los padres, porque están viniendo obligados; incluso han venido algunos acompañados por algún adulto y les han dejado aquí... Como vienen obligados, no hay un acatamiento de las normas" (profesional de entidad pública).
Además de estos actores ajenos a la protección, es un 'saber común' entre quienes trabajan con los menores solos que hay, al menos, dos escenarios en los que el trabajo social no sabe o no puede intervenir: la infracción y las redes de explotación. La infracción jurídica de menores solos tutelados ${ }^{20}$ es un indicio más de la tendencia de esta migración a alejarse y resistirse a la institucionalización. El trabajo social reacciona con perplejidad ante este itinerario y desarrolla discursos que lo simplifican, al vincular al conjunto de los menores solos acogidos con la infracción. Por el contrario, la investigación ha concluido que las infracciones cometidas por menores solos se concentran en un pequeño número de jóvenes reincidentes, que generan la base del discurso uniformizador ${ }^{21}$.

Sin embargo, en lo que coinciden la observación, los menores y los técnicos es en que los menores solos infractores tienen más dificultades para renovar sus permisos de residencia una vez alcanzan la mayoría de edad, por la discrecionalidad en la tramitación de éstos ${ }^{22}$. Otra práctica de bioselección hacia quienes no se adaptan a los itinerarios estandarizados, común en todas las comunidades autónomas.

El otro escenario al margen de la protección es el transitado por los menores y, especialmente, las menores que llegan a Aragón mal acompañadas por redes de explotación, y que provienen principalmente del África subsahariana y de Europa del Este. En este caso, es el trabajo social de las entidades sociales el que interviene más intensamente con las menores vinculadas a estas redes a la prostitución, el ámbito más opaco al sistema de protección. Y tal y como concluyen los profesionales que atienden estas situaciones de invisibilización, es necesario y urgente modificar las prácticas administrativas de detección y acogida de estas menores, para evitar la salida de los centros a las que no quieren formar parte de unas redes que las desplazan contra su voluntad por la geografía del Estado (Alonso, 2008, 2010; Justicia de Aragón, 2010: 133).

El año pasado, en una redada en un club, se detectó a una menor... y se le llevó al COA [Centro de Observación y Acogida, Zaragoza] [...]. La niña, en los pocos días que estuvo, verbalizó una tragedia... Que, obviamente, estaba allí en su contra,... pero tenía mogollón de pánico, y a los dos días los dejaron en la calle [a sus proxenetas], fueron al COA y se la llevaron..., porque eran su padre y su hermano (profesional de entidad privada).

${ }^{20}$ Este apartado de la investigación puede consultarse en Gimeno Monterde (2012a).

${ }^{21}$ De las 50 infracciones atribuidas a menores solos en 2010, 35 correspondían a jóvenes a los que se había abierto un nuevo expediente por infracción ese mismo año. Uno de ellos había cometido siete infracciones, y otros dos fueron sancionados en cinco y cuatro ocasiones, respectivamente. El resto de los reincidentes acumulan tres o dos infracciones anuales (Gimeno Monterde, 2012a: 267).

22 "Las autorizaciones de residencia 'es una locura total' cuando son mayores de $18 . .$. Si tienen delitos..., les llega denegado por informes" (profesional de entidad pública). 


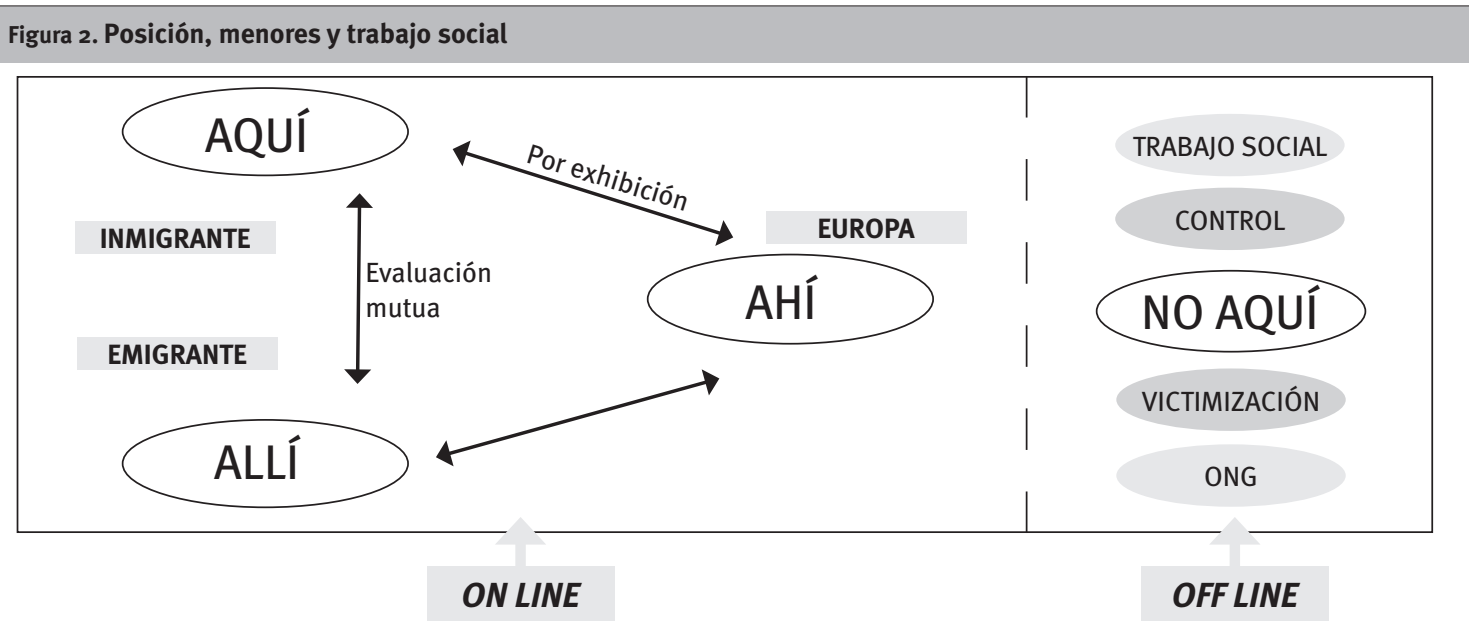

Fuente: Elaboración propia.

\section{9. Éxodo y posición}

Recapitulando, los intentos de abordar la presencia de estos actores y escenarios desde un trabajo social implícitamente posicionado como herramienta de control migratorio, que intenta limitar los itinerarios, uniformándolos, se han encontrado siempre con nuevas estrategias de resistencia (Suárez Navaz, 2006: 8; Bergua, 2007: 35). Estos nuevos desbordamientos de los jóvenes que migran solos no pretenden ningún cambio, en un sentido moderno, sino desertar de los conflictos con el Estado, lo que vuelve a desconcertar al trabajo social.

A este éxodo frente al orden ${ }^{23}$, la investigación ha accedido alejándose de la posición como profesional o técnico, compartiendo con jóvenes que migraron solos las redes sociales virtuales. Es ahí donde hemos constatado que, por debajo de las representaciones simbólicas de victimización y uniformización que el trabajo social ha establecido off line para los menores solos, éstos han desarrollado una subversión imaginaria ${ }^{24}$ amparada en las socialidades, esto es, en lo estético y lo afectivo ${ }^{25}$.

${ }^{23}$ Describiendo este éxodo, Paolo Virno (2003: 72) afirma que el "caldo de cultivo de la desobediencia son los conflictos sociales que se manifiestan no sólo, y no tanto, como protesta, sino más bien como defección [...], no como voice, sino como exit. [...] La defección [...], en lugar de afrontar el problema eligiendo una de las alternativas previstas, cambia el contexto en el cual se inserta el problema. El exit consiste en una inversión desprejuiciada que altera las reglas del juego y hace enloquecer la brújula del adversario". ¿Cómo se manifiesta esta defección? Para Bergua (2005: 33), "la resistencia y la producción de novedad que protagonizan la gente, el pueblo, en la actualidad se efectúa desde lo imaginario".

${ }^{24} \mathrm{Si}$ la situamos en términos de lo instituido en el trabajo social, esta victimización podríamos identificarla con la tradición, una tradición cuya legitimidad no será cuestionada, pues esta posibilidad se considera psíquicamente imposible. Por el contrario, el imaginario instituyente, como el que aquí intuimos, se aleja de la repetición, pues puede hacer lo que quiere (Castoriadis, 1993). Los perfiles virtuales muestran que las aparentes víctimas pueden transformar las imposiciones (el imaginario instituido) en creaciones propias, formas culturales híbridas que pueden estar, a la vez, dentro y fuera (Bergua, 2005: 32).

25 Véase Bergua (2007: 12; 2005: 39), para el que el "ascetismo revolucionario ha sido sustituido por el hedonismo estético”. La ló-
En el imaginario de las redes sociales virtuales conviven referencias globales de consumo ${ }^{26}$, de afectividad transnacional, así como de rabia y frustración frente a algunas etapas de la migración. En las redes nos hemos encontrado, en definitiva, a unos jóvenes globales que quieren ser "primer mundo" (BennaniChraïbi, 1998: 27), algo que no han logrado en su lugar de origen e intentan conseguir aquí, en Europa.

A ellos queremos dar las gracias y dedicar esta investigación. A los jóvenes que migran solos, a esos jóvenes que han invertido en su viaje sus mejores años, arriesgando a menudo su único capital, sus propios cuerpos. Jóvenes de los que los científicos y los trabajadores sociales creemos saber algo. Una migración que se aleja constantemente del equilibrio, de la que poco o nada sabemos.

\section{Agradecimientos}

A Carlos Gómez Bahillo y Aurora López Azcona, de la Universidad de Zaragoza, por la dirección de esta investigación. Al Instituto Aragonés de Servicios Sociales, por aportar los datos sobre los expedientes de tutela, así como por facilitar el contacto con los profesionales. A las entidades públicas y privadas que han colaborado, así como a sus técnicos. $Y$ especialmente a todos los y las menores que han participado aportando su testimonio.

gica 'conjuntista' de las ciencias sociales clásicas que informan a la Administración pretende organizar conjuntos basados en la búsqueda de lo idéntico. Éste es el caso de los 'perfiles' de menores solos. De esta manera, no capta sino un fragmento estático de la realidad (el "No aquí" de la Figura 2), donde la creatividad, tan presente en las redes sociales virtuales, está ausente.

${ }_{26}$ Para Maffesoli (2004: 109), el hedonismo, el carpe diem y otras expresiones de la actual expansión de lo existencial son contrarias a las ideologías y acciones en las que todavía se mueven políticos, 'trabajadores sociales' y otros poderes públicos. Muestran, además, una "cierta reticencia antropológica hacia todos los poderes, que no deja de expresarse puntualmente con mayor o menor eficacia según el tiempo y el lugar". 


\section{Referencias bibliográficas}

ADCARA (2008): “Diagnóstico de la inmigración en Aragón. Área de infancia y juventud", en GÓMEZ BAHILLO, C. (coord.), Estudio diagnóstico de la situación de la inmigración en Aragón 2007, Zaragoza, Gobierno de Aragón, Departamento de Asuntos Sociales y Familia [cederrón].

ALONSO, A. (2010): "En tierra de nadie. Migración y prostitución entre adolescentes no acompañadas de Europa del Este en Cataluña”, Educación Social, nํㅜ 45, págs. 65-77.

- (2008): En terra de ningú. Una aproximació a la prostitució en els projectes migratoris de menors no acompanyades de l'Europa de l'Est a Catalunya [tesina de máster], Universitat Autònoma de Barcelona.

ARAGÓN (2008): “Decreto 190/2008, de 7 de octubre, del Gobierno de Aragón, por el que se aprueba el Reglamento de medidas de protección de menores en situación de riesgo o desamparo", Boletín Oficial de Aragón, no 174, 23-10-2008, págs. 21347-21372 [<http://bit.ly/18iZ8fM>].

BENNANI-CHRAÏBI, M. (1998): Soumis et rebelles, les jeunes au Maroc, París, CNRS Éditions.

BERGUA, J. A. (2011): Estilos de la investigación social. Técnicas, epistemología, algo de anarquía y una pizca de sociosofía, Zaragoza, Prensas Universitarias.

- (2007): Lo social instituyente. Materiales para una sociología no clásica, Zaragoza, Prensas Universitarias.

- (2005): “Lo social instituyente y la imaginación”, Culturales, $\mathrm{n}$ - 1 , págs. 29-56.

CABRERA, J. C. (2005): Acercamiento al menor inmigrante marroquí, Sevilla, Junta de Andalucía.
CASTORIADIS, C. (1993): El mundo fragmentado Encrucijadas del laberinto III, Buenos Aires Montevideo, Altamira - Nordan.

CAYUELA, S. (2008): “¿Biopolítica o tanatopolítica?”, Daímon, no 43 , págs. 33-49.

COMITÉ SOBRE LOS DERECHOS DEL NIÑO DE NACIONES UNIDAS (2005): Observación no 6 (2005). Trato de los menores no acompañados y separados de su familia fuera de su país de origen, CRC/ $\mathrm{GC} / 2005 / 6$, Nueva York, Naciones Unidas, Comité sobre los Derechos del Niño [«http:// tb.ohchr.org/default.aspx?Symbol=CRC/ $\mathrm{GC} / 2005 / 6>$ ].

- (s/f): Committee on the Rights of the Child - General Comments, Nueva York, Naciones Unidas, Comité sobre los Derechos del Niño [«http:// www2.ohchr.org/english/bodies/crc/ comments.htm〉].

DURÁN, F. J. (2007): “Las administraciones públicas ante los menores extranjeros no acompañados: entre la represión y la protección", Revista Electrónica de la Facultad de Derecho de la Universidad de Granada, junio [<http://www.refdugr.com/ documentos/articulos/4.pdf)].

EMPEZ, N. (2009): “The fieldworker as a social worker: dilemma's in research with Moroccan Unaccompanied minors in Spain", en VAN LIEMPT, I.: y BILGER, V. (ed.), The Ethics of Migration Research Methodology. Dealing with Vulnerable Immigrants, Eastbourne, Sussex Academic Press.

- (2007): Social Construction of Neglect: The Case of Unaccompanied Minors from Morocco to Spain, serie: MPIDR Working Papers, $\mathrm{n}$ 을 2007007 [<http://www.demogr.mpg.de/papers/ working/wp-2007-007.pdf)]. 
GIMENO MONTERDE, C. (2012a): "Menores que migran solos e infracción en Aragón”, Revista de Derecho Migratorio y Extranjería, no 29, págs. 263-283.

- (2012b): “Expectativas de acogida, éxito y fracaso. El imaginario de los menores que migran solos", en II Congreso Internacional sobre Diagnóstico y Orientación. Jaén, 8-10 de marzo de 2012, Jaén, págs. 603-630 [<http:// dl.dropboxusercontent.com/u/4393023/actas. pdf\#page $=603$ > $]$.

- (2011): "El orden y la gente: los menores migrantes no acompañados”, en GIMÉNEZ RODRÍGUEZ, GARCÍA MANSO, A.; y DÍAZ CANO, E. (coords.), Innovaciones en la sociedad del riesgo, Toledo, Asociación Castellano Manchega de Sociología.

- (2010): “Menores extranjeros no acompañados: una cuestión compleja para las políticas públicas y sociales", Revista de Derecho Migratorio y Extranjería, no 25 , págs. 55-72.

IASS; y ADCARA (2005): La actuación con familias y menores de origen extranjero en situación de riesgo, Zaragoza, Instituto Aragonés de Servicios Sociales [<http://www.adcara.org/ PDFs/6FamiliasExtranjeras.pdf $>$ ].

JIMÉNEZ ÁLVAREZ, M. (2011): “Intrusos en la fortaleza. Menores marroquíes migrantes en la frontera sur de Europa" [tesis doctoral], Universidad Autónoma de Madrid.

JIMÉNEZ ÁLVAREZ, M.; y VACCHIANO, F. (2011): “De dependientes a protagonistas. Los menores como sujetos migratorios", en RIBAS, N. (coord.), El río Bravo mediterráneo: las regiones fronterizas en la época de la globalización, Barcelona, Bellaterra [citado repaginado].

JUSTICIA DE ARAGÓN (2010): Sugerencia relativa a la determinación de la edad de los menores extranjeros no acompañados, expediente: DI-1563/2010-1, Zaragoza, Justicia de Aragón [rhttp://www.eljusticiadearagon.com/gestor/ ficheros/resoluciones/_noo4841_201001563. pdf〉].

- (2007): Informe sobre la situación de los menores en Aragón, serie: Informes Especiales [<http:// www.eljusticiadearagon.com/gestor/ficheros/_ noo3325_menores2007.pdf〉].

- (2003): Informe sobre la situación de los menores en Aragón, serie: Informes Especiales [rhttp:// www.eljusticiadearagon.com/gestor/ficheros/_ no01355_Menores.pdf〉].

- (2002): Informe sobre la situación de los menores en Aragón, serie: Informes Especiales [khttp:// www.eljusticiadearagon.com/gestor/ficheros/_ noo0458_Menores.pdf〉].

- (2001): Informe sobre la situación de los menores en Aragón, serie: Informes Especiales [«http:// www.eljusticiadearagon.com/gestor/ficheros/_ noo0153_menores.pdf $\rangle]$.

- (2000): Informe sobre la situación de los menores en Aragón, serie: Informes Especiales [«http:// www.eljusticiadearagon.com/gestor/ficheros/_ noo0152_Menores.pdf〉].

LÓPEZ AZCONA, A. (2008): “El tratamiento de los menores extranjeros no acompañados en el Derecho español”, en Revista de Derecho Migratorio y Extranjería, noำ18, págs. 103-134.
LÓPEZ RIOPEDRE, J. (2011): "El proceso de victimización de la trabajadora sexual migrante" [comunicación], International Conference on Negotiating Identity in Migration Processes, octubre, Madrid, CSIC [inédito].

MAFFESOLI, M. (2004): El tiempo de las tribus, México D. F., Siglo XXI.

MONTEROS, S. (2007): "La construcción social de un nuevo sujeto migratorio: los menores migrantes marroquíes no acompañados" [tesis doctoral], Universidad Autónoma de Madrid.

OBSERVATORIO DE LA INFANCIA (2005): Protocolo de Menores Extranjeros no Acompañados (según acuerdo adoptado en la reunión del Grupo de MNA de 14 de Noviembre, 2005), Madrid, Ministerio de Trabajo y Asuntos Sociales, Observatorio de la Infancia [<http://www. observatoriodelainfancia.msssi.gob.es/ documentos/Protocolo_MENA_2005.pdf)]).

O'HIGGINS, A. (2012): “Vulnerability and agency: Beyond an irreconcilable dichotomy for social service providers working with young refugees in the UK", New Directions for Child and Adolescent Development, $\mathrm{n}$ ำ136, págs. 79-91.

QUIROGA, V. (dir.) (2010): Sueños de bolsillo. Menores migrantes no acompañados/as en España, Barcelona, Unicef; Banesto [rhttp://www. unicef.es/sites/www.unicef.es/files/Suenos_ de_bolsillo.pdf〉].

QUIROGA, V.; y SORIA, M. (2010): “Los y las menores migrantes no acompañados/das: entre la indiferencia y la invisibilidad", Educación Social, nํㅜ 45, págs. 13-35.

RODRÍGUEZ GARCÍA DE CORTÁZAR, A. (2008): "Reacciones y relaciones de menores y jóvenes marroquíes ante la protección y la exclusión", E-Migrinter, $\mathrm{n}^{0} 2$ [<http://www.mshs.univpoitiers.fr/migrinter/e-migrinter/200802/ emigrinter2008_02_153.pdfs].

RODRÍGUEZ GARCÍA DE CORTÁZAR, A.; y GONZÁLEZ SANTAMARÍA, E. (2011): "El cuerpo para 'buscarse la vida'. Prácticas corporales de jóvenes migrantes marroquíes en procesos de exclusión", en GARCíA CASTAÑO, F. J.; y KRESSOVA, N. (coords.), Actas del I Congreso Internacional sobre Migraciones en Andalucía, Granada, Instituto de Migraciones [rhttp:// migraciones.ugr.es/congres02011/libroacta/ Mesa10/006_RodriguezGonzalez.pdf〉].

SASSEN, S. (2003): Contrageografías de la globalización. Género y ciudadanía en los circuitos transfronterizos, Madrid, Traficantes de Sueños.

SUÁREZ NAVAZ, L. (2008): “La perspectiva transnacional en los estudios migratorios. Génesis, derroteros y surcos metodológicos", en GARCíA ROCA, J.; y LACOMBA, J. (eds.), La inmigración en la sociedad española. Una radiografía multidisciplinar, Barcelona, Edicions Bellaterra.

- (2006): “Un nuevo actor migratorio: jóvenes, rutas y ritos juveniles transnacionales", en CHECA, F.; ARJONA, A.; y CHECA, J. C. (eds.), Menores tras la frontera. Otra inmigración que aguarda, Barcelona, Icaria.

- (2004): "Inmigración de los menores migrantes no acompañados”, en DONCEL, C.; y QUIROGA, V. 
(dirs.), Actas del I Seminario Europeo Menores Migrantes No Acompañados en Europa,

Fundación Pere Tarrés, Universidad Ramon Llull [<http://www2.peretarres.org/daphneconred/ estudi/actas/pdf/actas.pdf>].

SUÁREZ NAVAZ, L.; y JIMÉNEZ ÁLVAREZ, M. (2011): “Menores en el campo migratorio transnacional. LoS niños del centro (Drari d'sentro)", Papers, nํ 96/1, págs. 11-33.

VIRNO, P. (2003): Gramática de la multitud. Para un análisis de las formas de vida contemporáneas, Madrid, Traficantes de Sueños. 